\title{
Practical Experiences with the First Relative Gravimeter of Type Scintrex CG-6 Autograv in Dubai, The United Arab of Emirates
}

\author{
Ossama S. Aly ${ }^{1,2}$, Basem Elsaka ${ }^{2,3}$, Eman A. Al Khatibi ${ }^{1}$ \\ ${ }^{1}$ Geodesy and Hydrographic Survey Section, Dubai Municipality, Dubai, The United Arab of Emirates \\ ${ }^{2}$ National Research Institute of Astronomy and Geophysics (NRIAG), Cairo, Egypt \\ ${ }^{3}$ Institute of Geodesy and Geoinformation, University of Bonn, Bonn, Germany \\ Email: osmohamed@dm.gov.ae
}

How to cite this paper: Aly, O.S., Elsaka, B. and Al Khatibi, E.A. (2020) Practical Experiences with the First Relative Gravimeter of Type Scintrex CG-6 Autograv in Dubai, The United Arab of Emirates. World Journal of Engineering and Technology, 8, 237-247.

https://doi.org/10.4236/wjet.2020.82019

Received: April 29, 2020

Accepted: May 22, 2020

Published: May 25, 2020

Copyright (๑) 2020 by author(s) and Scientific Research Publishing Inc. This work is licensed under the Creative Commons Attribution-NonCommercial International License (CC BY-NC 4.0). http://creativecommons.org/licenses/by-nc/4.0/

\begin{abstract}
In September 2019, the Dubai Municipality of Dubai Emirate, the United Arab of Emirates, has received its first Scintrex CG-6 Autograv gravity meter. This paper describes the installation and initial gravity signals with the new CG-6 Autograv gravimeter. Two gravity field sites have been selected at Dubai City and Hatta mountainous area. The relative gravity field measurements have been recorded for about one month time span; two weeks at Dubai and two weeks in Hatta. Among different effects reducing the gravity measurements, the tide and drift corrections have been focused on within this paper. Two tidal models have been applied to reduce the tide effect based on the automated ETGTAB of the CG-6 gravimeter and ETERNA3.3 software. The results regarding the tide correction show very small discrepancies between both models (ETGTAB and ETERNA3.3) of about $2.2 \mu \mathrm{Gal}$ and $2.6 \mu \mathrm{Gal}$ in terms of standard deviations at Dubai and Hatta gravity stations, respectively. So, the outcome of the precise tidal model of CG-6 Autograv gravimeter is reliable for tidal reduction within Dubai area and its surroundings. Regarding the drift correction, the CG- 6 Autograv provides low instrument drift values about $2.44 \mu \mathrm{Gal}$ and $-2.35 \mu \mathrm{Gal}$ per day for the Dubai and Hatta stations, respectively. Furthermore, it is recommended that the Hatta gravity station would be considered as a stable and trusted gravity site. For Dubai gravity station, the gravity observations are affected by some noises from traffic activities while recording the gravity signal during the working days. Therefore, it is recommended for Dubai gravity station to be measured during the weekends and at nights in order to avoid any noises affecting the CG- 6 gravimeter.
\end{abstract}

\section{Keywords}

Terrestrial Gravity Field, Scintrex CG6 Autograv, Drift Correction 


\section{Introduction}

In the Geodesy and Hydrographic Survey Section of Dubai Municipality (DM) located at Dubai Emirate, the United Arab of Emirates (UAE), precise groundbased measurements are quite important for establishing the DM's vision and mission. Creating an excellent city that provides the essence of success and comfort of living is the DM's vision. Working to plan, build, design and manage the municipal infrastructure and other related facilities and services through the appropriate investment in our human and other resources is the DM's Mission. This can be performed through accurate measurements which accordingly require accurate devices to achieve the related service. For this goal, the DM has purchased the recent generation of the relative gravimeters; namely the Scintrex CG-6 Autograv gravity meter (gravimeter) manufactured by the Canadian Company SCINTREX [1] to obtain accurate gravity measurements.

Prior to the CG-6 Autograv, there were other Autograv instruments. The first fully automated relative gravimeter (Autograv) has been initiated since 1984, when the Canadian company Scintrex Ltd. (Concord, Ontario) has developed Autograv CG-3 [2]. The Scintrex CG-3 Autograv was followed in 1990 by CG-3M ([3] [4] [5]) for mineral exploration, oil and gas exploration and microgravity and geodetic applications. In 2005, a new generation, namely Scintrex CG-5 Autograv [6] with a reading resolution of $1 \mu \mathrm{Gal}\left(1 \mu \mathrm{Gal}=10^{-8} \mathrm{~m} / \mathrm{s}^{2}\right)$ and a worldwide measurement range of over $8 \mathrm{Gals}$ has been developed. We have to mention here that the unit of gravity is $\mathrm{m} / \mathrm{s}^{2}$ in the SI (System International) and in the cgs (centimetre gram second) system is Gal unit $\left(1 \mathrm{Gal}=1 \mathrm{~cm} / \mathrm{s}^{2}\right.$, named after Galileo Galilei (1564-1642)) for gravity measurements. The findings of our paper will be given in $\mu \mathrm{Gal}$ unit which is preferable for regional and local gravity survey.

A new design, Scintrex CG-6 [1], is in the market since 2016, whose reading resolution reaches $0.1 \mu \mathrm{Gal}$. Unlike CG-3 and CG-5, the CG- 6 is supported by a 7-inch tablet computer, which is prepared for field use with Windows 7 (32 bit) as well the "LYNX LG Land Gravity" software to allow the observer to monitor and control the measurement remotely during the data capture. In October 2019, the Dubai Municipality became the first relative gravimeter of type Scintrex CG-6 Autograv in Dubai Emirate, the UAE.

The CG-6 Autograv as shown in Figure 1 is placed on a pillar in the basement of the Dubai Municipality. Figure 2 shows the location of two gravity stations; Dubai and Hatta, where the CG-6 will continuously measure the gravity field differences. The acquired local data from CG-6 will serve in combination with globally available satellite data for the derivation of accurate gravity field models of Dubai city specifically and the United Arab of Emirates.

In this article, practical experiences of the first the CG-6 Autograv Gravity meter in Dubai Emirate, the UAE are described. In the following, a short review about the hardware and software characteristics of the CG-6 is outlined in Section 2. In Section 3, the installation and test measurement are described. Section 4 discusses the initial results. Finally, conclusions are provided in Section 5. 


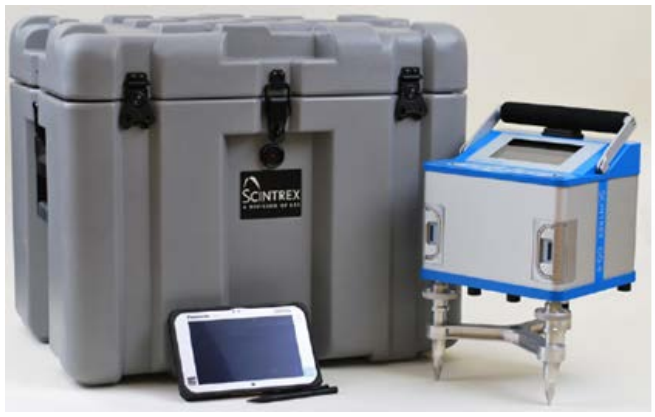

(a)

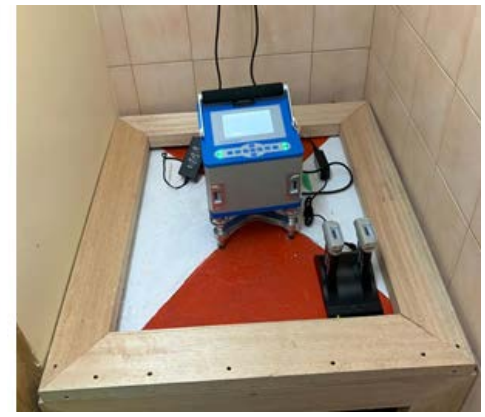

(b)

Figure 1. (a) The Scintrex CG-6 Autograv as given by Scintrex webpage and (b) as finally installed on a concrete pillar at the Dubai Municipality.

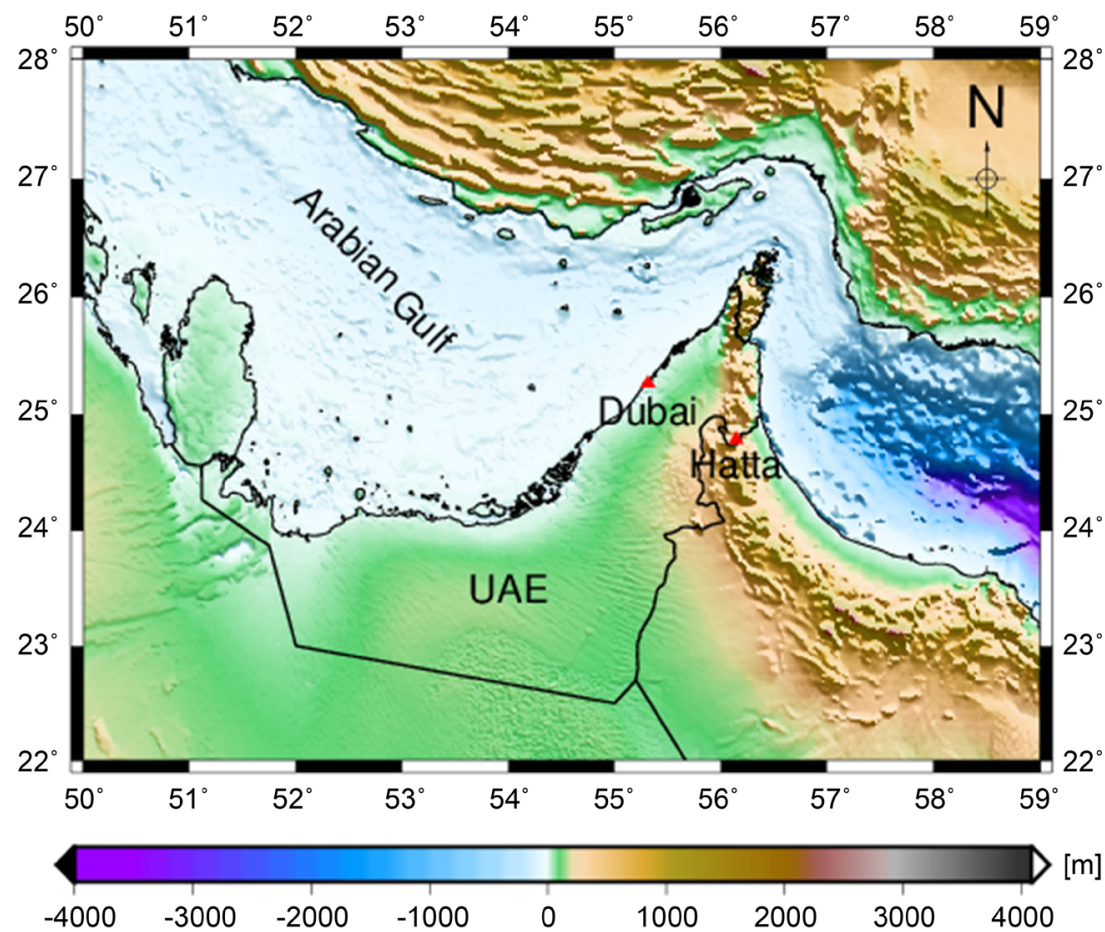

Figure 2. Topographic heights map [in meters] showing Dubai and Hatta gravity stations at Dubai Emirate, the UAE.

\section{Characteristics of CG-6 Autograv}

Basically, the principle of CG-6 Autograv is based on zero-position elastic spring gravimeter, which has a proof mass located in the middle of a capacitive transducer using an electrostatic nulling. In the course of measurement, an automatic feedback circuit applies DC voltage to the capacitor plates. The electrostatic force acting on the proof mass brings it back to the null position. The feedback voltage is proportional to relative value of gravity, which provides at the end the output in terms of gravity readings.

The new developed CG-6 Autograv [1] is characterized by some advantages, which were not in the former CG-series (e.g. CG-3 and CG-5) such as its current interfaces supported by USB, Wi-Fi and Bluetooth, which enables modern and 
fast data transfer and wireless connection between CG-6 and tablet, in addition to built-in GPS. The 7-inch tablet computer prepared for field use with Windows 7 (32 bit) as well the "LYNX LG Land Gravity" software allows the observer to monitor and control the measurement remotely during the data capture. It should be noted here that the CG- 6 can be operated with or without a tablet. The connection between CG-6 and its tablet takes place via a Bluetooth connection, which is of course limited to about 7 meters. In addition, the CG- 6 is characterized by its low sensor height of about $6.6 \mathrm{~cm}$ with respect to (w.r.t.) $8.9 \mathrm{~cm}$ at CG- 5 above the bottom plate of the gravimeter, where the gravity value will be measured closer at the reference point. In total, the CG-6 reduced device height (21.5 $\mathrm{cm}$ opposite $30 \mathrm{~cm}$ w.r.t. CG-5) provides thereby less susceptibility to wind. Moreover, the CG-6 has lower weight of about $5.5 \mathrm{~kg}$ w.r.t. the CG-5, whose weight is about $8 \mathrm{~kg}$. The CG-6 is equipped with a tripod to adjust the leveling and two rechargeable lithium smart batteries $(2 \times 6.8 \mathrm{Ah}(10.8 \mathrm{~V}))$ which allow a full day operation at $25^{\circ} \mathrm{C}\left(77^{\circ} \mathrm{F}\right)$. The large membrane keypad of the CG- 5 was on the CG- 6 by a small keyboard replaced with four arrows and a confirmation button.

Unlike the CG-5, the leveling of CG-6 takes place via two-foot screws (Figure 1), which are located below the front of the Gravimeter. Both the necessary direction of rotation of the foot screws and the quality of the leveling are of two multicolored (LED) arrows, which are also visible in unfavorable lighting conditions. In addition, the LED display shows the state of charge of the batteries, which can be according to the manufacturer operated for about full day at an ambient temperature of $25^{\circ} \mathrm{C}$, however, the duration would be lowered to about 10 hours with at lower temperatures of about $10^{\circ} \mathrm{C}$.

It is worthwhile noting here that the Dubai Municipality has received a high temperature version of the CG- 6 Autograv gravimeter with an operating temperature range of $-40^{\circ} \mathrm{C}$ to $+55^{\circ} \mathrm{C}$ in order to endure the temperature circumstances of the Gulf region. New in the CG-6 Autograv is the stable solid aluminum handle, which differs from the previous version of CG-6 that was made of textile fabrics strap. This makes it much easier for hand transport and installation.

\section{Site Preparation and Gravity Measurement}

\subsection{Site Preparation}

In order to set up our Scintrex CG-6 Autograv instrument, new site in the basement of the DM building to be easily accessible all the times has been firstly established. A concrete pad sized $80 \mathrm{~cm} \times 80 \mathrm{~cm}$ and $100 \mathrm{~cm}$ depth was constructed reaching the bedrock, which is suitable for both relative and absolute gravity measurements (for future calibration). A marker is installed on the concrete pad as shown in Figure 3.

It should be mentioned here that the Dubai Emirate consists of two main regions; the main Dubai city and the Hatta area as shown in Figure 2. One of our 

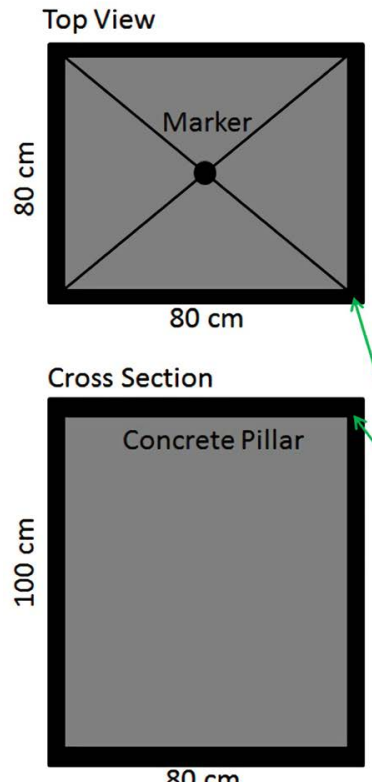

$80 \mathrm{~cm}$
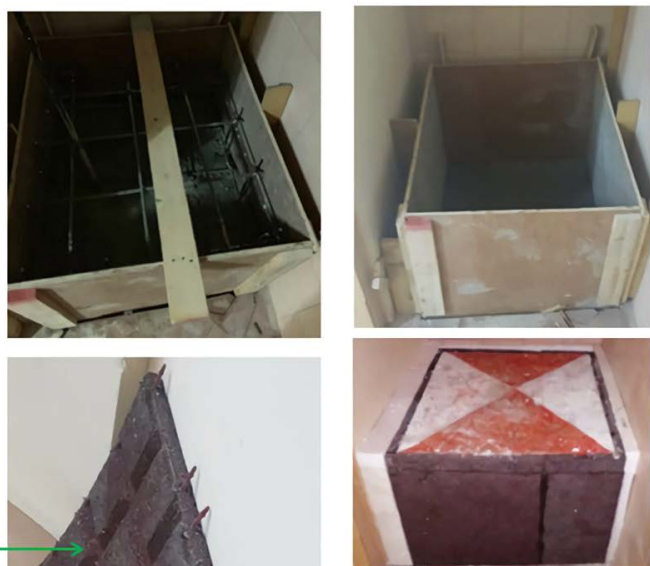

Isolation material
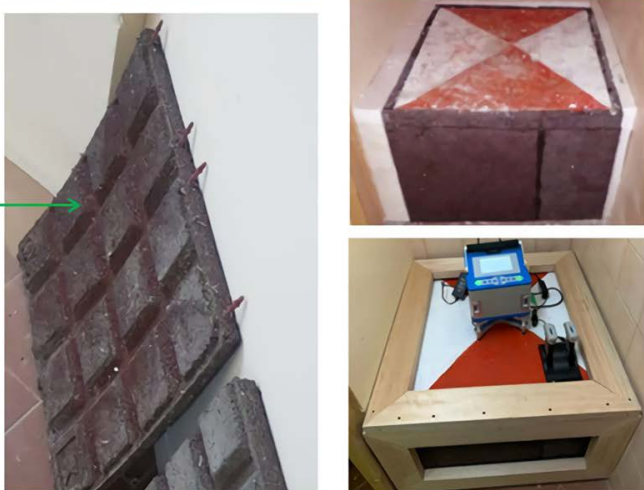

Figure 3. A sketch (left) showing the establishment of the concrete pillar (right) for the gravity station in the DM's basement.

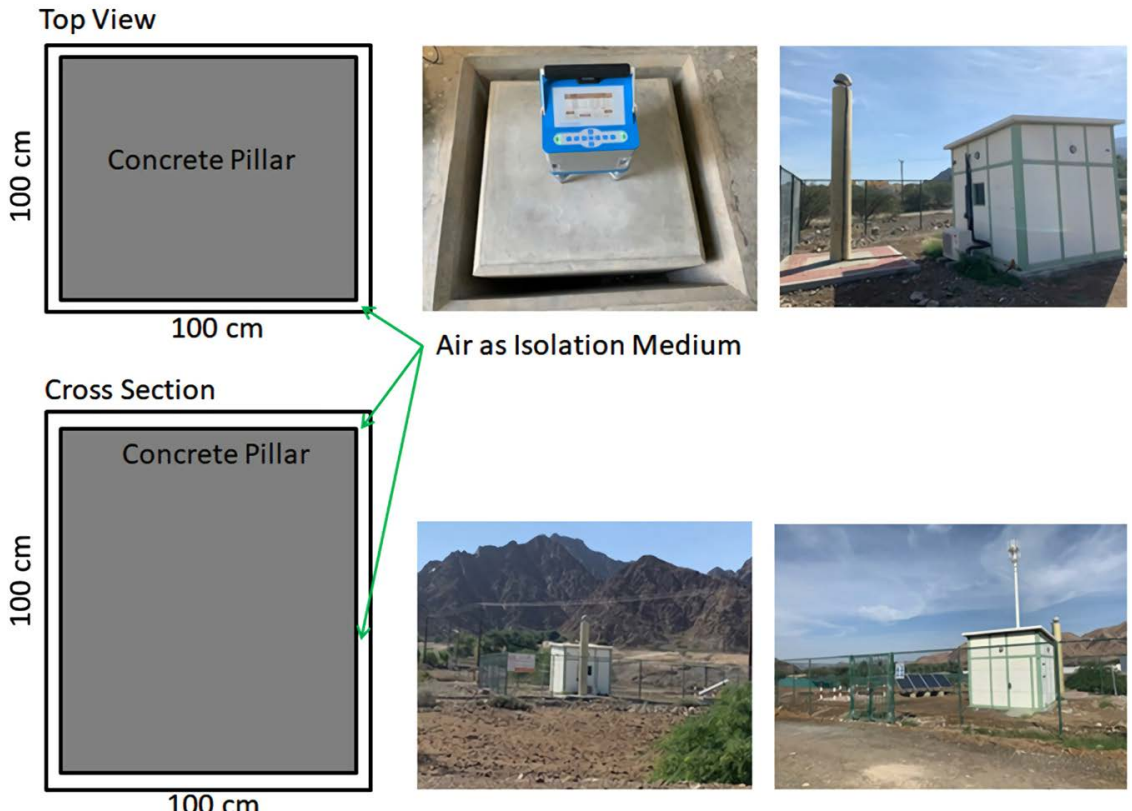

Figure 4. A sketch (left) of the concrete pillar (middle) for the Hatta gravity station.

main interests is to tie the gravity readings of Dubai City with Hatta area, and therefore, a gravity station has been also installed there as shown in Figure 4. The main advantage of Hatta gravity station is that, it is located in quiet mountainous area which is supported with differential global positioning system (GPS) based on virtual reference station (VRS) techniques and a DC power. This latter advantage allows continuous long-term gravity observations. 


\subsection{Gravity Measurement}

The relative gravity measurements at Dubai and Hatta gravity stations were carried out using the CG-6 Autograv relative gravimeter between December 2019 and January 2020 in order to investigate the long period recorded gravity signal. The gravimeter was set up first at Dubai gravity station for about 17 days followed by 18 days in Hatta station. Before recording the gravity, all automated corrections of our Scintrex CG-6 Autograv gravimeter have been enabled including temperature, drift, tide, tilt corrections. The acceptable gravity readings were recorded every 60 seconds. The gravity readings have been read and processed using programming code which is written by the authors using GNU Octave Software Version 5.1 (http://www.octave.org). For more details, please contact Basem Elsaka, the University of Bonn, elsaka@uni-bonn.de.

\section{Data Reduction and Initial Results}

\subsection{Correction of Effects Reducing the Gravity Field}

In order to analyze and interpret gravity data accurately, gravity readings have to be firstly reduced and corrected from numerous influences [7]. Some of these influences must be pre-processed independent on the target of the gravity survey and others are processed dependently on the survey target. The influences that should be considered in the pre-processing step are for instance instrumental height, instrumental drift, tides and ocean loading, air pressures. One means here with pre-processing that the gravity data must be corrected before processing the gravity data from other influences affecting the gravity measurements such as latitude variation, heights (free-air correction), mass change and terrain (simple and detailed Bouguer corrections), and isostatic and topographic corrections, etc. Since our Scintrex CG-6 Autograv gravimeter is installed at the station for long time span, we will be focusing in the following section on the tidal effect and instrumental drift.

\subsection{Correction of Tides and Instrument Drift}

The CG-6 Autograv as mentioned in the introductory section is based on zero-position elastic spring which may be affected by temporal changes due to some reasons. This effect is called gravimeter drift. Possible reasons for a drifting zero-position are addressed by [7] and [8] such as aging process of spring material, external temperature changes, and uncompensated changes of atmospheric pressure and elastic hysteresis effects due to vibrations, shocks and inclinations acting on the measurement system during transport.

Before applying drift correction, the gravity raw data are mainly affected by the Earth tide, which is a subject to the attraction of the Sun and the Moon with the other celestial bodies to the Earth's body. This effect reaches to about \pm 300 $\mu \mathrm{Gal}$. Therefore, one must first reduce the tidal effect in order to be able to detect the variation in range of tens of $\mu$ Gals accuracy due to the drift effect. 
In this paper, two tidal corrections for both Dubai and Hatta gravity stations have been applied. The first correction is based on the automated ETGTAB tide correction of the Scintrex CG-6. The other tide correction has been estimated based on the ETERNA3.3 software [9], where tidal parameters have been driven from gravity tide amplitudes of the [10] tidal potential. Figure 5 and Figure 6 show the tidal effects in terms of mGal as well as the differences of tide corrections as computed from both ETGTAB and ETERNA3.3. The discrepancies between both applied tidal calculations (using ETGTAB and ETERNA3.3) given in Table 1 are very small of about $2.2 \mu \mathrm{Gal}$ and $2.6 \mu \mathrm{Gal}$ in terms of standard deviations (Std.) for Dubai and Hatta gravity station, respectively. Therefore, the computed received tide correction from the automated ETGTAB is reliable for our gravity observation target.

Regarding the drift correction, Figure 7 and Figure 8 show the gravity data analysis before and after applying the tide and drift corrections for both Dubai and Hatta gravity station, respectively. Regarding to the Dubai gravity station, the black curve of Figure 7 shows the raw gravity data as corrected from temperature and tilt providing a sinusoidal behavior resulted from the tidal effect. After subtracting the tidal effect (given in Figure 5) from the black curve of Figure 7 using the tide corrections as computed by ETGTAB and ETERNA3.3, the red and blue curves have been attained, respectively. However, still both curves show a remaining trend, which is interpreted here as drift signal of about $2.44 \mu \mathrm{Gal} /$ day. Therefore, the drift trend has been subtracted from the reduced gravity signal (red curve) to provide the green curve which is now corrected

Table 1. Statistics showing the discrepancies between automated ETGTAB of the Scintrex CG-6 Autograv and ETERNA3.3 software at Dubai and Hatta gravity stations. Units in $\mu \mathrm{Gal}$.

\begin{tabular}{ccccc}
\hline \multirow{2}{*}{ Station } & \multicolumn{4}{c}{ Statistical values } \\
\cline { 2 - 5 } & $\mathrm{SD}$ & mean & min. & max. \\
\hline Dubai & 2.255 & 0.0328 & -4.936 & 5.270 \\
Hatta & 2.661 & 0.0279 & -5.762 & 6.304 \\
\hline
\end{tabular}

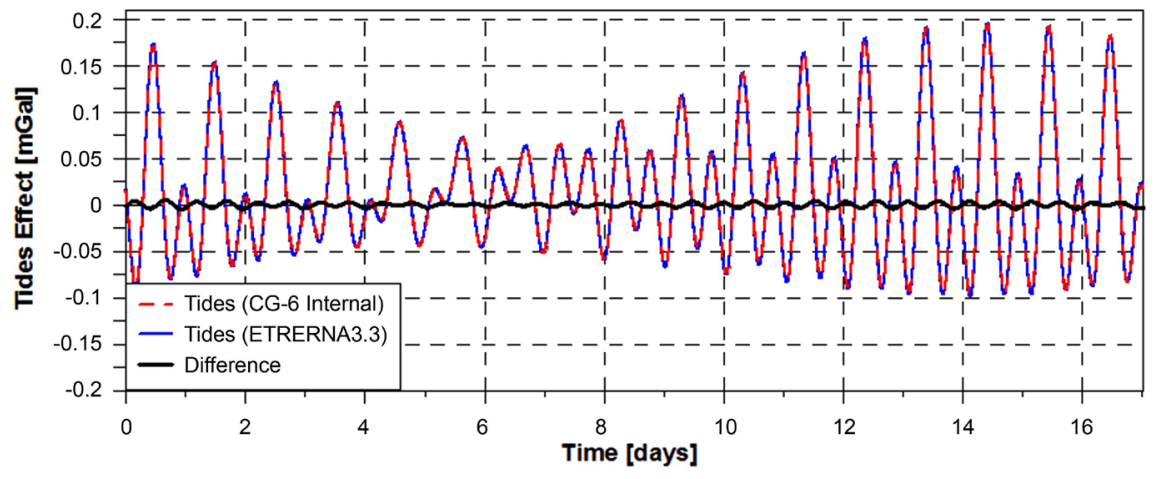

Figure 5. Tidal effects in mGal as detected from CG-6 and computed using ETERNA3.3 Software for Dubai gravity station. 


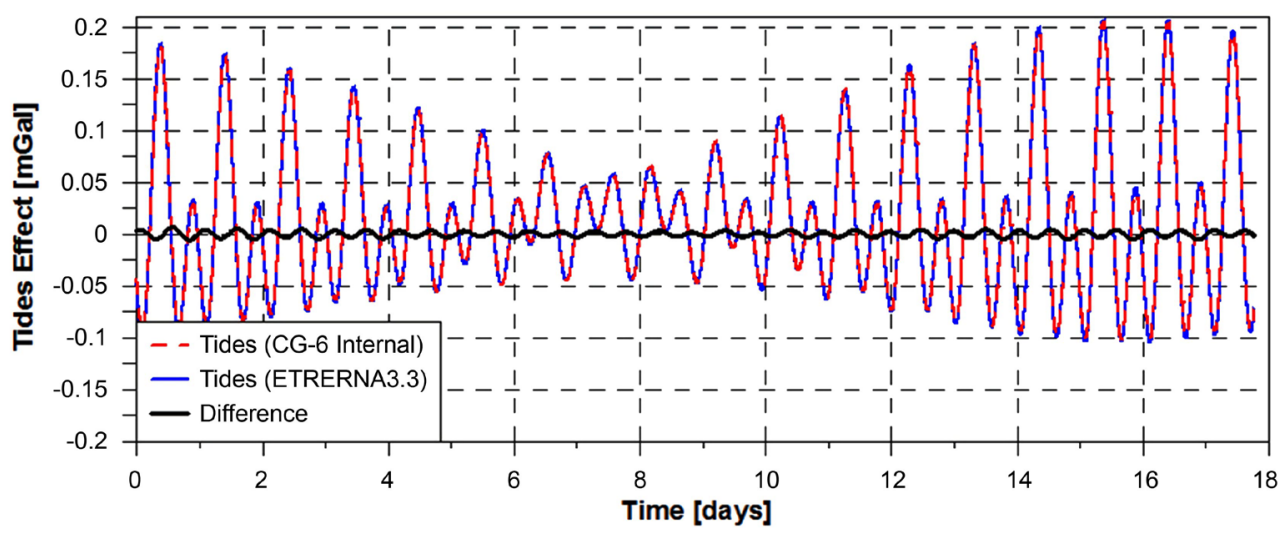

Figure 6. Tidal effects in mGal as detected from CG-6 and computed using ETERNA3.3 Software for Hatta gravity station.

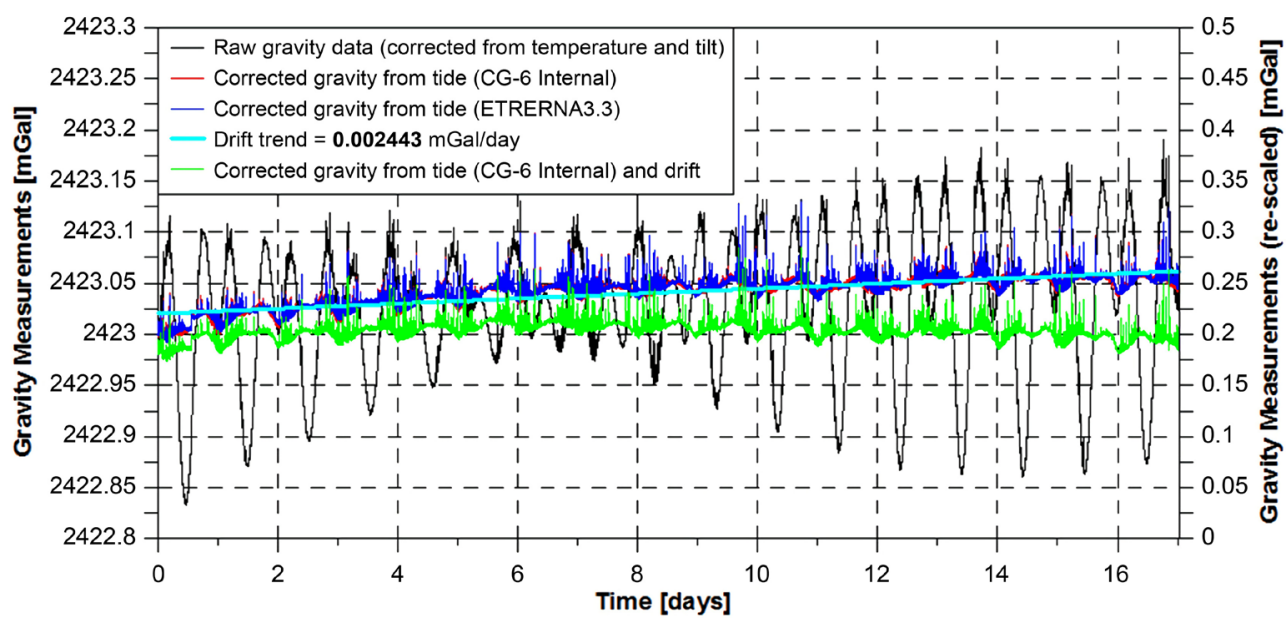

Figure 7. Corrected gravity field signal from tides and instrument drift of Dubai gravity station.

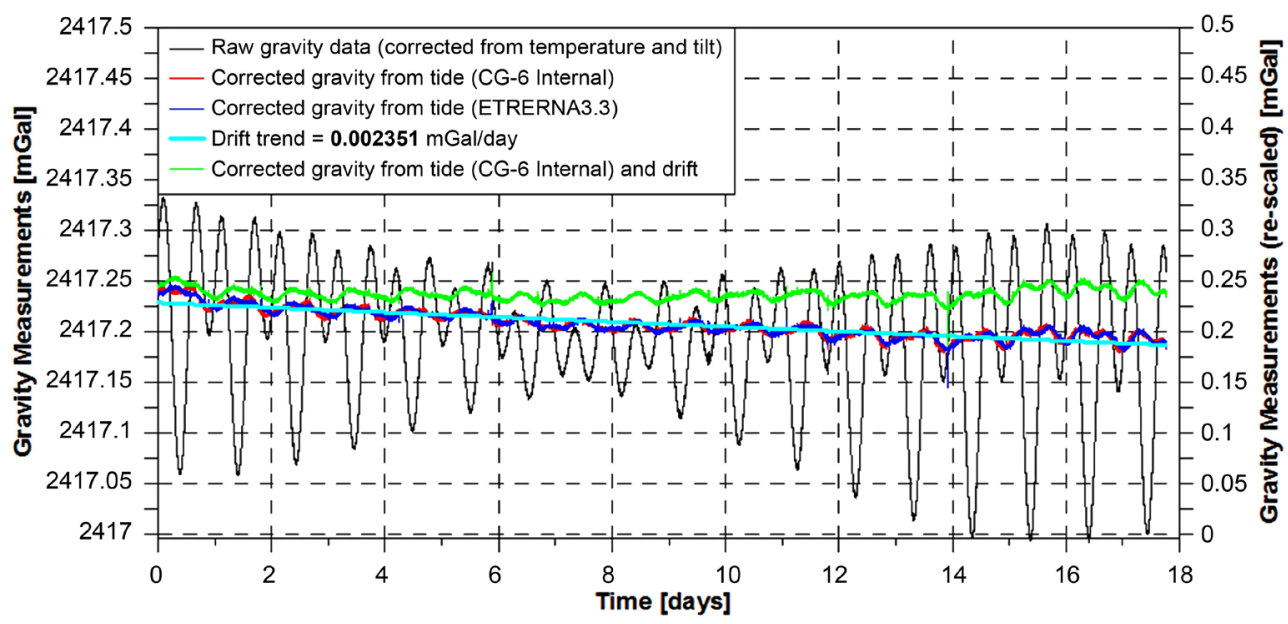

Figure 8. Corrected gravity field signal from tides and instrument drift of Hatta gravity station.

from both tide and drift effects. Same thing has been applied for the Hatta gravity station as shown in Figure 8 showing a relatively lower drift behavior of about $-2.35 \mu \mathrm{Gal} /$ day. 
Comparing Figure 7 and Figure 8, one can conclude first that the Scintrex CG-6 Autograv gravimeter provides a lower drift in few $\mu$ Gals per day than the device accuracy given by the manufacturer. Moreover, the Dubai gravity station provides a noisy gravity signal as represented in Figure 7 with respect to the Hatta station represented in Figure 8. This may due to that the Dubai gravity station is installed in the basement of Dubai Municipality's main building located on the side of main traffic road. However, it can be accepted as stable gravity station if gravity observations have been carried out at night, where rare traffic flows. To prove this, Figure 9 and Figure 10 show two examples of different one-day gravity observations recorded in working and weekend days, respectively. As seen from Figure 9, the gravity observations during the working day' activities (Monday 02 ${ }^{\text {nd }}$ December 2019) from 6 am till $10 \mathrm{pm}$ provide a noisy signal except at night hours. Figure 10, representing gravity measurements of a weekend day (Saturday 14 ${ }^{\text {th }}$ December 2019), has relatively short-period noisy signal compared to the normal working day.

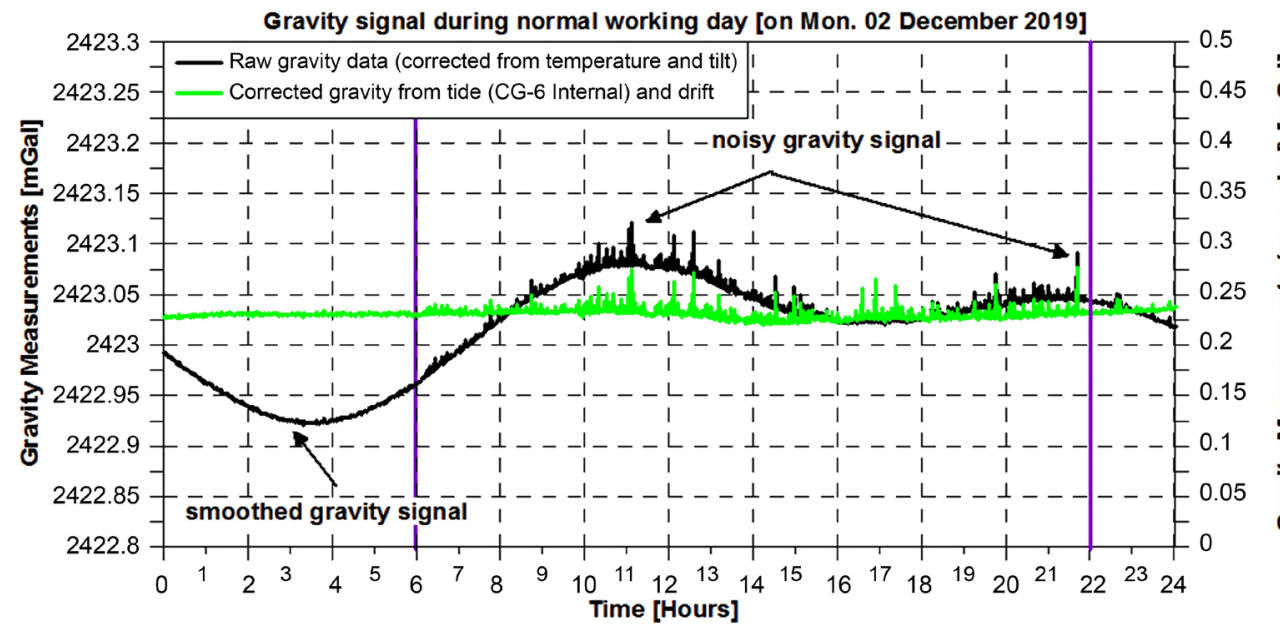

Figure 9. Gravity field signal in normal working day (Monday 02.12.2019) at Dubai gravity station.

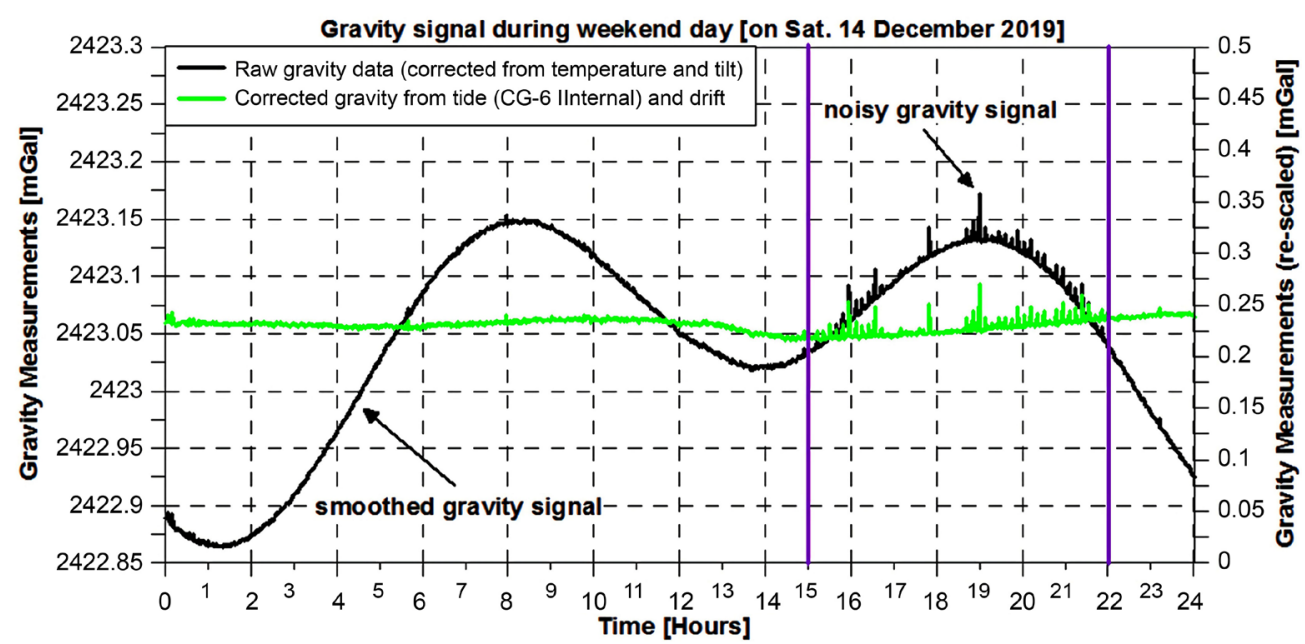

Figure 10. Gravity field signal in weekend day (Saturday 14.12.2019) at Dubai gravity station. 
To sum up, the Dubai and Hatta stations are considered to be trusted gravity stations for collecting gravity observations, especially for Hatta area, since it is away from noises. In addition, it is recommended for Dubai gravity station to be measured during the weekends and at nights in order to avoid any traffic noises affecting the Scintrex CG-6 gravimeter.

\section{Conclusions}

In this article, practical gravity observations with the first Scintrex CG-6 gravity instrument in Dubai Emirate, the United Arab of Emirates have been established. The gravity field variations at two main stations in Dubai and Hatta mountainous area have been recorded within a time span of one month (about two weeks for each of them). Regarding the Dubai gravity station, the site has been prepared by installing a concrete pillar at the basement of the Dubai Municipality's main building.

Among different effects reducing the gravity measurements, the corrections regarding the tide and drift effects have been applied. Regarding to the tide correction, a comparison between the tidal effects estimated by the CG-6 internal software (ETGTAB) and by ETERNA3.3 software has been accomplished. The differences in terms of standard deviations have been found in range of about $2.2 \mu \mathrm{Gal}$ and $2.6 \mu \mathrm{Gal}$ at Dubai and Hatta gravity station, respectively. Thus, one can conclude that the ETGTAB tidal model of CG-6 Autograv gravimeter is a reliable model for tidal reduction within Dubai area and its surroundings.

Regarding the drift correction, one can conclude that the CG-6 Autograv behaves even more stable and provides quiet gravity measurement with low drift values of about $2.44 \mu \mathrm{Gal} /$ day and $-2.35 \mu \mathrm{Gal} /$ day for the Dubai and Hatta stations, respectively. Furthermore, it has been found that the Hatta station is considered as a stable and trusted gravity site because of its undisturbed location. For Dubai gravity station, some noises have been recorded when measuring gravity during the working days. Therefore, it is recommended to Dubai gravity station to be measured during the weekends and at nights in order to avoid any traffic noises affecting the Scintrex CG-6 Autograv gravity meter.

\section{Acknowledgements}

The authors would like to thank Mr. Mohammed Mashroom, the Director of Survey Department of Dubai Municipality for his scientific and innovative support, which improves the quality of survey output.

\section{Conflicts of Interest}

The authors declare no conflicts of interest regarding the publication of this paper.

\section{References}

[1] Reigber, C., Schwintzer, P. and Lühr, H. (1999) The CHAMP Geopotential Mission. 
Bolletino di Geofisica Teorica ed Applicata, 40, Article ID: 285289.

[2] Hugill, A. (1984) The Design of a Gravimeter with Automatic Readout. Ph.D. Thesis, Flinders University, Bedford Park, South Australia.

[3] Hugill, A. (1990) The Scintrex CG-3M Autograv Automated Gravity Meter: Description and Field Results. Society of Exploration Geophysicists 1990 Annual Meeting, San Francisco, CA, Expanded Abstracts GM 1.8, pp. 601-604. https://doi.org/10.1190/1.1890276

[4] Scintrex (1995) Scintrex User's Guide CG-3/3M Gravity Meter. Scintrex Ltd., Concord, Ontario, Canada.

[5] Seigel, H.O., Brcic, I. and Mistry, P. (1995) A High Precision, $\mu$ Gal Resolution, Land Gravimeter with Worldwide Range. In: Seigel, H.O. (Ed.), A Guide to High Precision Land Gravimeter Surveys. Scintrex Ltd., Concorde, Ont, 120.

[6] Scintrex (2012) CG-5 Operation Manual-Part \#867700 (Revision 8). Canada.

[7] Torge, W. (1989) Gravimetry. De Gruyter GmbH, Berlin, New York.

[8] Timmen, L. and Gitlein, O. (2004) The Capacity of the Scintrex Autograv CG-3M No. 4492 Gravimeter for Absolute-Scale Surveys. Revista Brasileira de Cartograa, 56,11 .

[9] Wenzel, H.-G. (1996) The Nanogal Software: Earth Tide Data Processing Package ETERNA 3.30. Bulletin d Informations Mareés Terrestres, 124, 9425-9439.

[10] Tamura, Y. (1987) A Harmonic Development of the Tide-Generating Potential. Bulletin d' Informations Mareés Terrestres, 99, 6813-6855. 